\title{
Analisa Kinerja TCP HYBLA pada Jaringan Wireless Mesh Network (WMN)
}

\author{
Riwanul Nasron ${ }^{1 *}$, Teuku Yuliar Arif ${ }^{2}$, dan Rizal Munadi ${ }^{3}$ \\ Magister Teknik Elektro, Universitas Syiah Kuala \\ riwalnasbci@gmail.com
}

\begin{abstract}
Abstrak - Wireless Mesh Network (WMN) merupakan topik penelitian yang menarik dan populer beberapa tahun terakhir. Jaringan WMN adalah jaringan komunikasi yang terdiri dari node mesh, router mesh, gateway, dan mesh klien. Jaringan yang dibentuk bisa berupa homogen dan juga heterogen. Kinerja WMN sangat berhubungan dengan TCP. Transport Control Protocol (TCP) adalah connection oriented protokol pada lapisan transport. TCP awalnya dirancang untuk jaringan kabel tetapi juga berkinerja baik dalam jaringan nirkabel. Untuk itu TCP Hybla hadir untuk bekerja pada jaringan yang heterogen. Untuk itu didalam penelitian ini akan dilakukan analisis kinerja TCP Hybla yang berjalan pada WMN. Penelitian ini menggunakan metode penelitian experimental dengan menggunakan network simulator NS-3 untuk mengetahui kinerja TCP Hybla pada WMN. Hasil dari penelitian ini adalah mendapatkan data kinerja TCP Hybla pada WMN yaitu throughput dan cwnd.
\end{abstract}

Kata kunci : $W M N, T C P, T C P$ Hybla, NS-3

Abstract - Wireless Mesh Network (WMN) has become interesting and popular topic for research lately. WMN is communication network consisting of node mesh, router mesh, gateway, and klien mesh. The formation network could be homogeneous or heterogeneous. WMN performance is quite related to TCP. Transport Control Protocol (TCP) is connection-oriented protocol in transport layer. TCP was initially designed for cable network, later on it also worked well in wireless network. Therefore, the presence of TCP Hybla is to work in heterogeneous network. So that, in this research, the performance of TCP Hybla running in WMN was analyzed. The research used experimental research with network simulator NS-3 to know the performance of TCP Hybla in WMN. The result was TCP Hybla in WMN consisting of throughput and cwnd.

Keywords: $W M N, T C P, T C P$ Hybla, NS-3

\section{Pendahuluan}

Wireless mesh Network (WMN) merupakan teknologi jaringan alternatif baru yang cukup potensial untuk dikembangkan dan sangat pesat perkembangannya karena berbagai keunggulan dan karakteristik yang dimilikinya dibandingkan dengan jaringan konvesional yang telah ada sebelumnya. WMN adalah jaringan komunikasi yang terdiri dari node mesh, router mesh, gateway, dan mesh klien. Semua disusun menjadi sebuah topologi mesh. WMN adalah teknologi nirkabel terbaik, dapat mendukung berbagai aplikasi, misalnya, jaringan broadband rumah, jaringan-jaringan komunitas dan lingkungan, jaringan perusahaan, membangun otomatisasi, perhotelan, bidang pendidikan, manajemen bencana, dan lain-lain [1]. Untuk melihat kinerja jaringan WMN perlu di perhatikan salah satunya pada protocol TCP yang bekerja.

Transport Control Protocol (TCP) adalah connection oriented protokol pada lapisan transport[12]. TCP menyediakan fitur penting dari flow control, reliabel, congestion control dan congestion managemen. TCP awalnya dirancang untuk jaringan kabel tetapi juga berkinerja baik dalam jaringan nirkabel.

Ada banyak varian TCP yang telah dikembangkan seperti TCP Reno, TCP New Reno, TCP Tahoe dan sebgainya. Hampir sebagian besar TCP tersebut bekerja lebih baik pada jaringan homogen. TCP Hybla difokuskan untuk mencegah putusnya koneksi yang disebabkan oleh adanya latency tinggi, Ide dasar dari TCP Hybla adalah untuk mendapatkan tingkat transmisi paket yang sama dari relatif koneksi varian TCP yang cepat [2]. Varian TCP Hybla merupakan varian TCP yang dibuat untuk jaringan heterogen, oleh karena itu sangat cocok di terapkan pada WMN dimana apabila jumlah node yang banyak merupakan bentuk dari jaringan heterogen. Sebelumnya pada [3] telah ada penelitian terkait TCP New Reno, TCP Jersey, dan TCP Tibet yang di terapkan pada WMN yaitu menyajikan kinerja terkait kualitas saluran. Pada [4] juga ada penelitian tentang penerapan varian TCP Tahoe yang diterapkan pada WMN dengan menganalisis kinerja varian TCP tersebut pada berbagai jumlah node. Juga pernah dilakukan penelitian tentang 
peningkatan kinerja beberapa varian TCP seperti TCP Vegas, Reno, New Jersey, dan lainya pada jaringan WMN dengan mengurangi retramision timeout [5]. Penelitian ini menggunakan network simulator NS3 [7] dalam mensimulasikan TCP Hybla pada WMN.

Di dalam penelitian ini, telah dilakukan analisis kinerja TCP Hybla yang berjalan pada jaringan WMN dan mendapatkan data kinerjanya terkait throughput dan cwnd agar dapat dilakukan optimasi dikemudian hari.

\section{Tinjauan Pustaka}

2.1. Wireless Mesh Network (WMN)

Wireless mesh network (WMN) saat ini telah menjadi sebuah arsitektur jaringan baru yang mampu memperluas jangkauan dan meningkatkan kapasitas akses terhadap jaringan wireless[13]. Pada dasarnya WMN adalah sebuah jaringan wireless yang secara khusus terdiri dari sejumlah mesh clients, gateway dan mesh routers. Biasanya mesh clients terdiri dari komputer, handphone, bluetooth dan peralatan wireless lainnya.

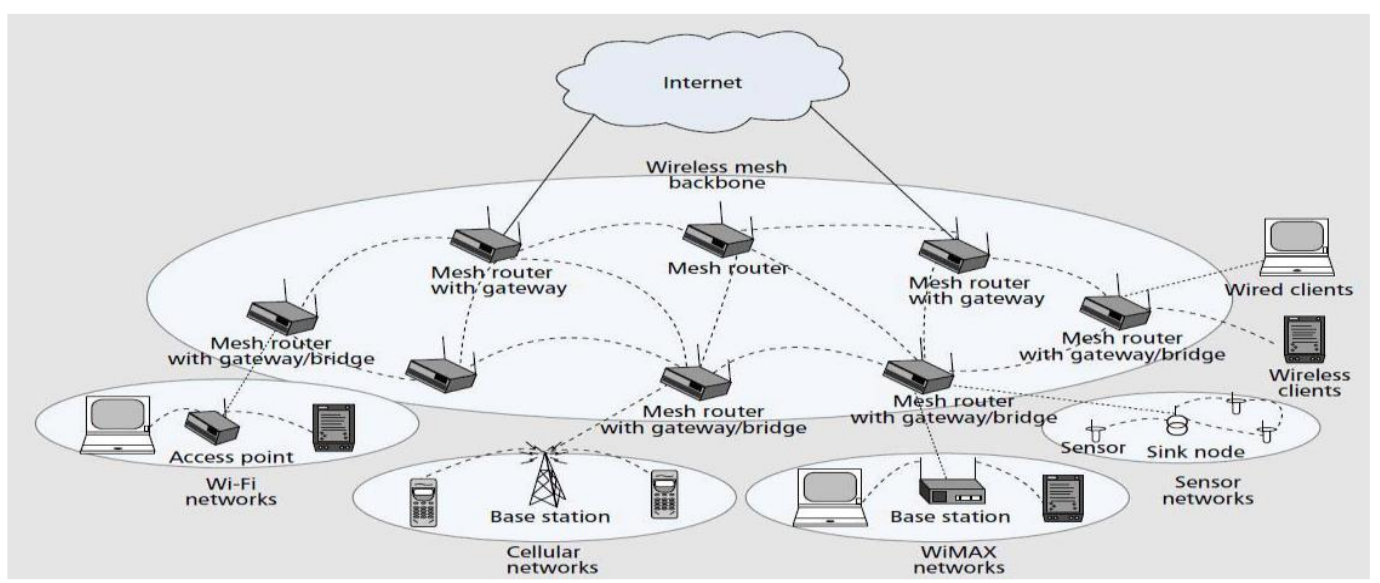

Gambar 1. Arsitektur Wireless Mesh Network [6]

\subsection{Transport Control Protocol (TCP)}

Transport Control Protocol (TCP) merupakan suatu protokol yang berada pada lapisan transport yang paling banyak digunakan karena menawarkan keaandalan connection-oriented dan layanan byte-stream [7]. TCP dispesifikasikan dalam RFC 793.

2.3. TCP Congestion Control

TCP Congestion Control [8] merupakan mekanisme kontrol end to end yang diimplementasikan untuk mengendalikan beberapa parameter yang mempengaruhi TCP Congestion Control diantaranya:

1. Congestion Window (cwnd) adalah ukuran jumlah paket yang dikirim dalam satu kali pengiriman

2. Slow Start Threshold (ssthresh) adalah ambang batas ukuran paket yang di kirim pada pase slow start

3. Round Trip Time (RTT) adalah waktu yang diperlukan dalam perjalanan sebuah paket dari dikirim dan diterima kembali.

4. Acknowledgement (ACK) adalah sebuah number yang dikirim oleh penerima sebagai pertanda sebuah pesan telah dikirim dengan baik.

\subsection{TCP Hybla}

Ide dasar dari TCP Hybla adalah untuk mendapatkan tingkat transmisi paket yang sama dari relatif koneksi varian TCP yang cepat [2]. TCP Hybla mengambil ide mengirim paket tanpa memperdulikan nilai RTT yang ada. Maka dibutuhkan sebuah variabel agar paket yang dikirimkan tidak terpengaruh dengan kondisi RTT, maka digunakan persamaan [2]:

$$
\rho=\mathrm{RTT} / \mathrm{RTT}_{0}
$$

Dimana $\mathrm{RTT}_{0}$ merupakan asumsi nilai RTT rata-rata pada koneksi tersebut RTT adalah estimasi RTT saat ini, dan $\rho$ dengan nilai minimal adalah 1 , atau dalam kasus ini RTT $\geq$ $\mathrm{RTT}_{0 .}$

\section{Metode Penelitian}

\subsection{Alur Penelitian}

Pada penelitan ini yang akan diteliti ialah bagian jaringan komputer terutama pada layer transport dengan objek penelitian yang akan diteliti adalah perfomasi wireless mesh network (WMN) dengan menganalisis parameter throughput dan cwnd. Alur penelitian yang ditempuh dapat dilihat pada gambar 2 . 


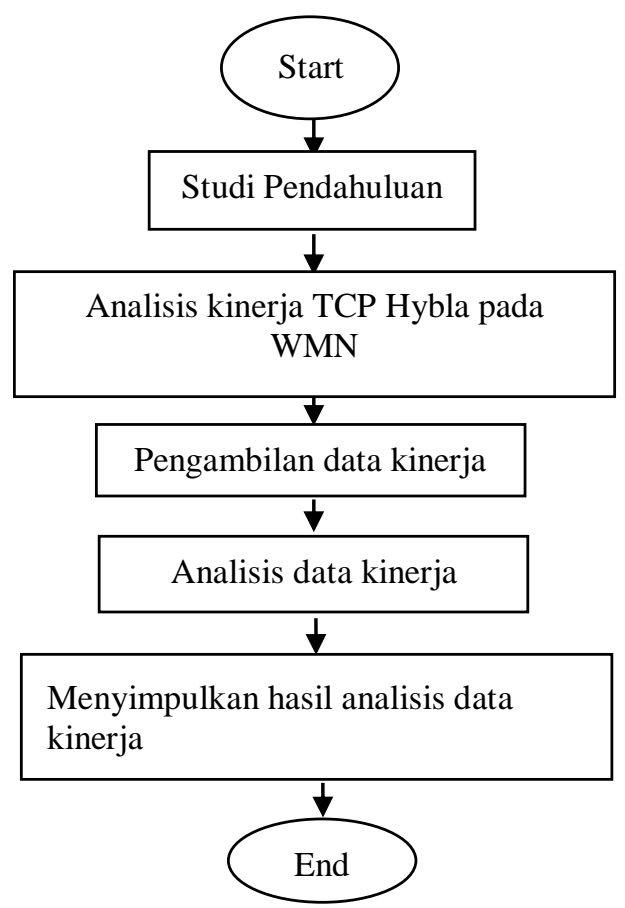

Gambar 2. Alur Penelitian

\subsection{Metode Penelitian}

Penelitian ini menggunakan metode kualitatif dengan menganalisis TCP Hybla untuk mendapatkan throughput yang optimal dan juga $c$ wnd yang optimal dari suatu jaringan WMN melalui simulasi terhadap jaringan tersebut menggunakan software, yaitu NS3[7]. Analisis dilakukan terhadap parameter jarak dan jumlah node yang dapat mempengaruhi nilai throughput dan cwnd. Dalam melakukan penelitian, perlu ada suatu kerangka berpikir agar mempermudah arah dari penelitian yaitu apa saja yang menjadi input dan apa outputnya seperti terlihat pada gambar berikut:

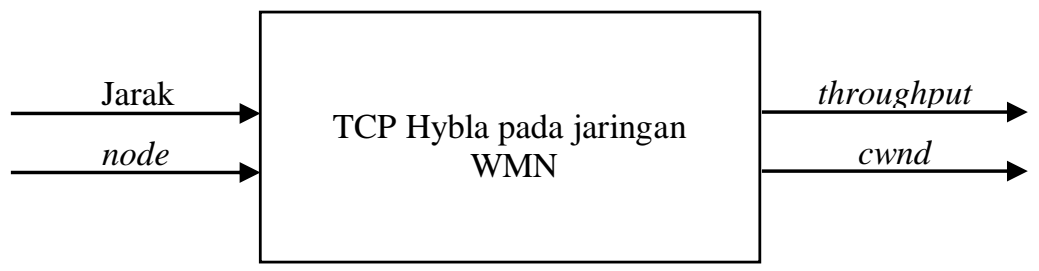

Gambar 3. Kerangka berpikir dalam metode penelitian

3.2.1 Pengujian Pengaruh Jarak dan Jumlah node Terhadap TCP Hybla

Pengujian pengaruh jarak dan jumlah node terhadap TCP Hybla dilakukan dengan mengevaluasi kinerja TCP Hybla pada jaringan WMN dengan memasukan parameter jarak dan jumlah node. Pada pengujian ini di dapatkan cara kerja TCP Hybla terhadap pengaruh dari jarak dan jumlah node.

Tahapan langkah yang dilakukan pada sebagai berikut :

1. Merancang topologi

Dalam penelitian ini, jaringan WMN terdiri dari beberapa node yang dibentuk dalam topologi grid [10], yaitu grid $1 \times 5$, $2 \times 5,3 \times 5,4 \times 5$, dan $5 \times 5$. 


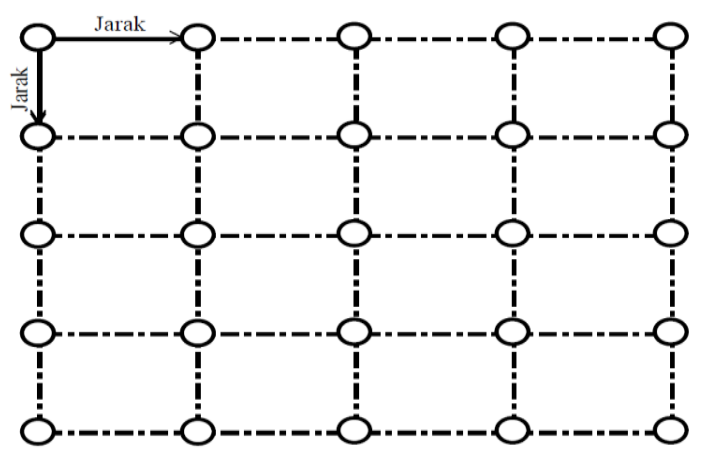

Gambar 4. Contoh Topologi grid [11]

Gambar diatas memperlihatkan contoh topologi grid. Jarak yang akan dilakukan pengujian adalah untuk jarak 10 meter sampai dengan 100 meter.

2. Menerapkan TCP Hybla

Selanjutnya pada topologi jaringan WMN tersebut, kemudian diterapkan TCP Hybla. Dari penerapan algoritma ini nantinya akan didapatkan throughput dan juga cwnd terhadap beberapa keadaan jarak dan jumlah node sebelum dilakukan pengujian terhadapa semua parameter untuk mendapatkan hasil yang optimal.

.Tabel 1. Tabel eksperimen

\begin{tabular}{|c|l|c|c|}
\hline \multicolumn{2}{|c|}{ Input } & \multicolumn{2}{c|}{ Output } \\
\hline Jarak & node & $\begin{array}{c}\text { throughput / } \\
\text { cwnd }\end{array}$ & waktu \\
\hline & & & \\
\hline
\end{tabular}

Tabel 1 merupakan langkah eksperimen yang akan dilakukan pada pengujian ini, dengan demikian dapat disimpulkan tahapan-tahapan yang dilakukan dalam pengujian paramater optimal ini adalah:

1. Mengevaluasi beberapa parameter yang lain

2. Paramater Optimal

Tahap ini dilakukan dengan mengubah nilai parameter jarak dan jumlah node untuk mendapatkan hasil througput dan cwnd yang paling optimal.

3. Penilaian hasil througput dan cwnd Penilaian hasil dilakukan untuk memonitoring hasil-hasil yang optimal

4. Pembuatan laporan

Akhir dari tahapan ini adalah pembuatan laporan.
3. Evaluasi

Pada tahapan ini nilai throughput dan cwnd adalah nilai dalam kondisi awal, nilai throughput dan cwnd yang diharapkan ialah dalam keadaan optimal. Parameter apa yang mempengaruhi dalam peningkatan nilai throughput [14] dan juga cwnd akan di teliti lebih jauh pada .

\subsubsection{Pengujian Paramater Optimal}

Untuk mempermudah pengujian akan dibuat tabel eksperimen

\section{Hasil Dan Pembahasan}

4.1 Perbandingan Throughput dan cwnd Terhadap Jarak

Untuk melihat perbandingan nilai throughput dan cwnd dengan peningkatan jarak, perlu sebuah grafik hubungan keduanya.

4.1.1 Perbandingan Throughput dan cwnd

Maksimum Terhadap Jarak

Pada gambar 5 dapat dilihat perbandingan nilai throughput maksimum pada setiap jarak yang di uji. Dari grafik bisa di lihat nilai throughput paling tinggi yang dihasilkan yaitu pada jarak 10 meter yaitu pada jumlah node 10 .

Untuk nilai $c$ wnd maksimum seperti pada gambar 6 terlihat kebalikan dari nilai throughput dimana pada jarak yang panjang dengan jumlah node yang banyak terjadi peningkatan nilai cwnd, ini disebabkan karakter TCP Hybla yang tidak memperdulikan RTT. Walaupun paket tidak memperoleh ACK paket yang lain terus dikirim. 


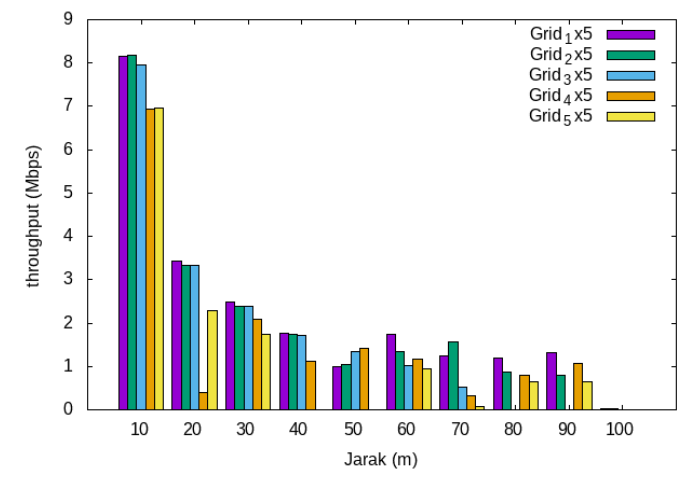

Gambar 5. Perbandingan Throughput

Maksimum Terhadap Jarak

4.1.2 Perbandingan Throughput dan cwnd Rata-Rata Terhadap Jarak

Untuk perbandingan nilai throughput dan

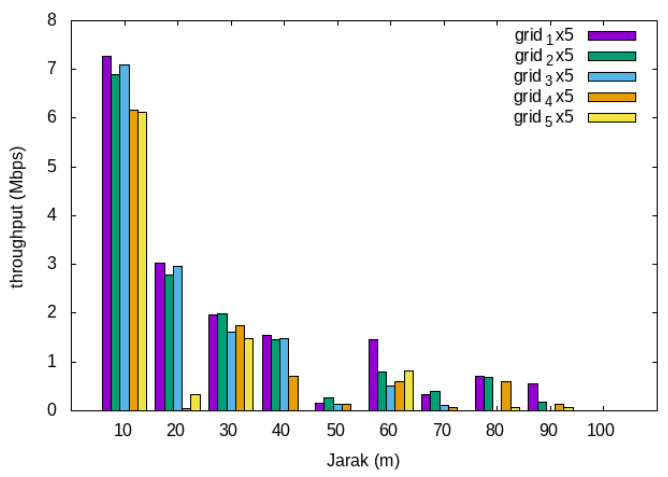

Gambar 7. Perbandingan Throughput Ratarata Terhadap Jarak

4.2 Perbandingan Throughput dan cwnd Terhadap Jumlah node

Untuk melihat perbandingan nilai throughput dan cwnd dengan peningkatan jumlah node, perlu sebuah grafik hubungan keduanya.

4.3.1 Perbandingan Throughput dan cwnd Maksimum Terhadap Jumlah node

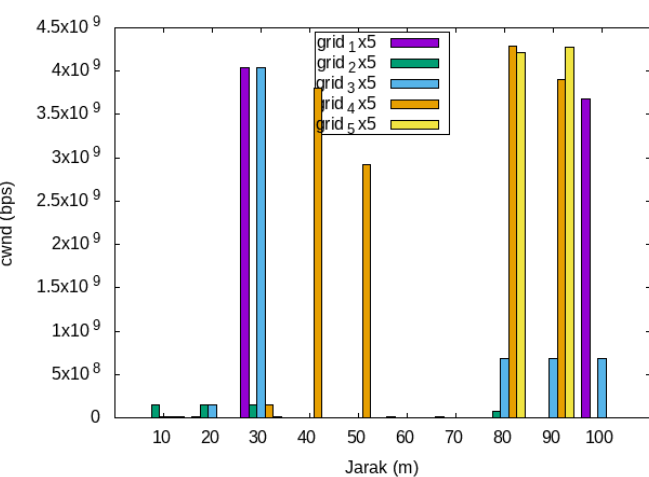

Gambar 6. Perbandingan cwnd Maksimum Terhadap Jarak

cwnd rata-rata dapat dilihat pada gambar 7 dimana jarak 10 meter masi menjadi nilai throughput yang paling tinggi dari jarak lainya.

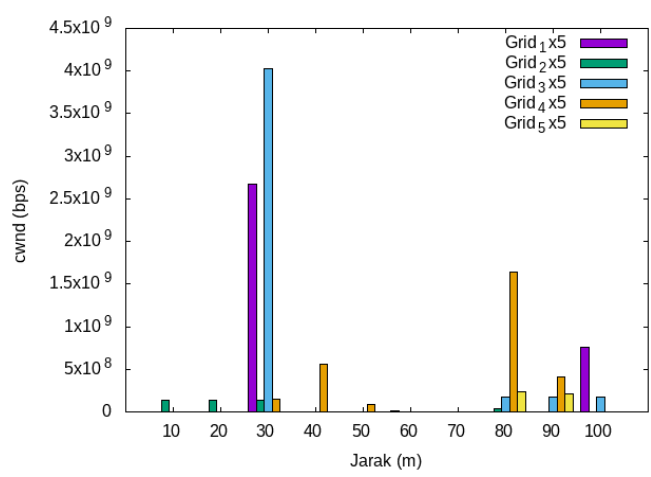

Gambar 8. Perbandingan cwnd rata-rata terhadap jarak

Pada gambar 9 menunjukan grafik perbandingan nilai throughput terhadap jumlah node dimana pada grafik terlihat throughput untuk semua jumlah node dari jumlah node 5 , 10, 15, 20, dan 25 dimana pada jarak 10 meter menghasilkan nilai throughput yang tinggi dengan nilai throughput diatas 7 Mbps. 


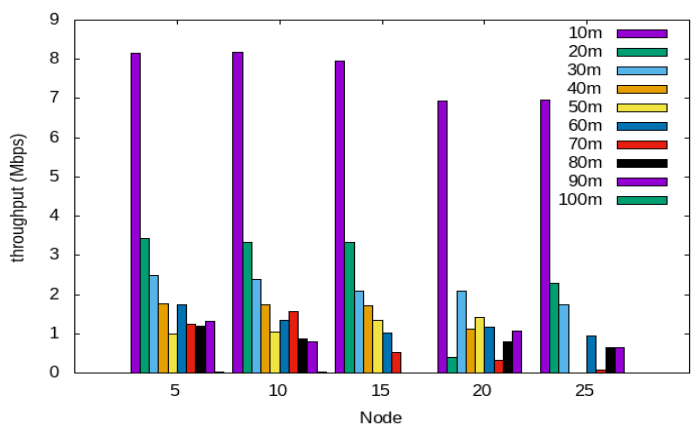

Gambar 9. Perbandingan throughput maksimum terhadap jumlah node

4.3.2 Perbandingan Throughput dan cwnd Rata-Rata Terhadap Jumlah node

Untuk perbandingan nilai throughput dan cwnd rata-rata bisa dilihat pada gambar 11 dan gambar 12 dimana nilai throughput yang bagus yaitu dengan jumlah node 5 dan 15 dengan jarak

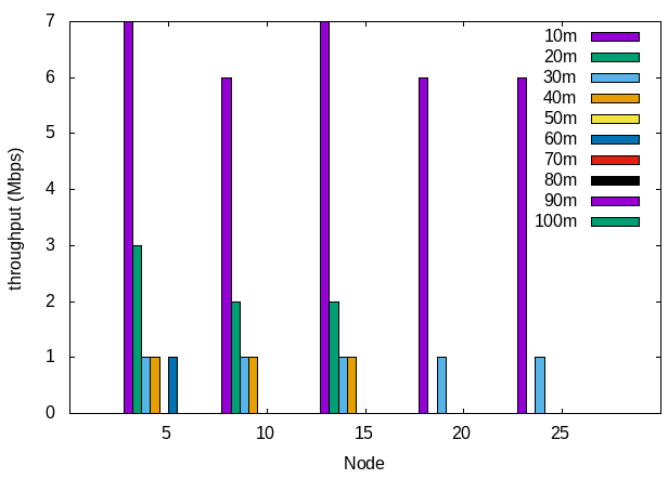

Gambar 11. Perbandingan throughput rata-rata terhadap jumlah node

\section{Kesimpulan}

Berdasarkan hasil pengujian dan evaluasi terhadap parameter tersebut diketahui bahwa TCP Hybla jika berjalan pada jaringan WMN apabila dilihat berdasarkan jarak bekerja lebih pada jarak 10 meter. Jika dilihat berdasarkan jumlah node kinerja TCP Hybla pada WMN bekerja lebih baik hampir di semua jumlah node.

Untuk tingkat kestabilan berdasarkan jarak maka TCP Hybla pad WMN bekerja stabil pada jarak 10, 20, dan 30 meter. Jika dilihat tingkat kestabilannya berdasarkan jumlah node maka pada jumlah node maka bekerja stabil hampir pada semua jumlah node.

Dengan demikian bisa disimpulkan bahwasanya untuk nilai throughput yang dihasilkan dari kinerja TCP Hybla pada WMN

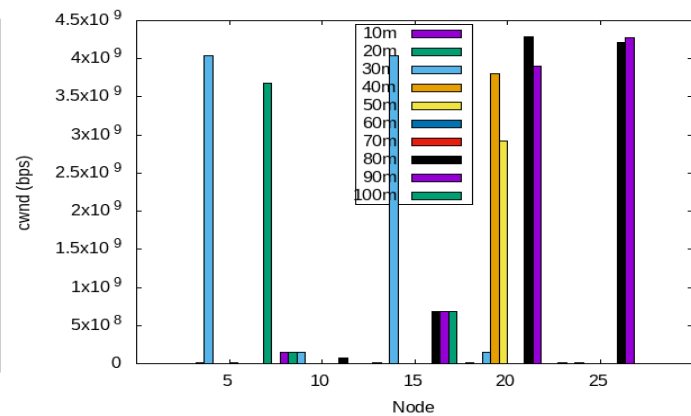

Gambar 10. Perbandingan cwnd maksimum terhadap jumlah node

10 meter. Untuk jumlah semua jumlah node dengan jarak besar dari 50 meter nilai rata-rata throughput yang dihasilkan 0. Ini disebabkan oleh panjangnya jarak mengakibatkan transmisi paket sering mengalami putus

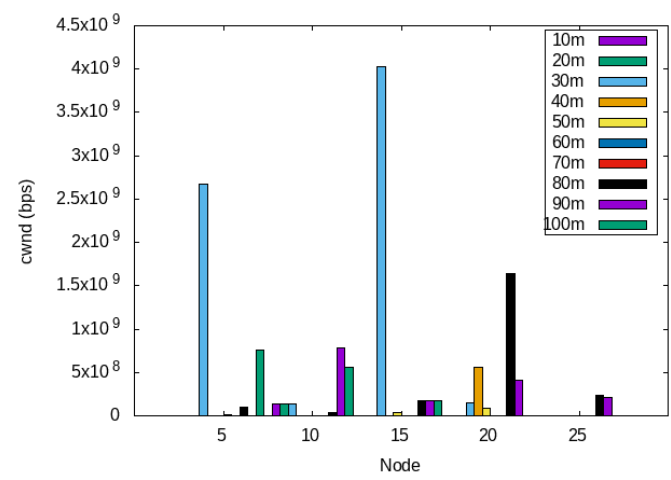

Gambar 12. Perbandingan $c$ wnd rata-rata terhadap jumlah node

sangat berpengaruh pada pertambahan jarak dan node.

\section{Daftar Pustaka}

[1] Karthika K.C, "Wireless mesh network: A survey," 2016 International Conference on Wireless Communications, Signal Processing and Networking (WiSPNET), Chennai, 2016.

[2] C. Caini and R. Firrincieli, "TCP Hybla: a TCP enhancement for heterogeneous networks," International Journal of Satellite Communication and Networking, vol. 22, no. 5, pp. 547-566, Sep. 2004.

[3] S. G. Colombo, T. Mandorino and G. Paltenghi, "TCP optimization in wireless mesh backhaul networks," 2008 3rd 
International Symposium on Wireless Pervasive Computing, Santorini, 2008.

[4] R. Unnikrishnan, S. R. Devi, R. Ramesh, A. Rajesh and A. Varma, "A comprehensive analysis of TCP congestion control schemes in wireless mesh networks," 2017 International Conference on Intelligent Computing, Instrumentation and Control Technologies (ICICICT), Kannur, 2017.

[5] Prasanthi. S, S.H. Chung and Y.H Jo, "A New Loss Recovery Algorithm for Increasing the Performance of TCP over Wireless Mesh Networks," 2012 26th IEEE International Conference on Advanced Information Networking and Applications, 2012

[6] M. Eslami, O. Karimi and T. Khodadadi, "A survey on wireless mesh networks: Architecture, specifications and challenges," 2014 IEEE 5th Control and System Graduate Research Colloquium, Shah Alam, 2014.

[7] project ns-3 Tutorial[EB/OL]. http://www.nsnam.org/, Desember 2014

[8] P.Lary, et al., Computer networks : a systems approach, Fourth Edition, Morgan Kaufmann Publishers, 2007

[9] Sun, Xiaoling, " TCP congestion control algorithm research," Information Science and Digital Content Technology (ICIDT), 2012 8th International Conference on , vol.3, no., pp.703,706, 26-28 Juni 2012

[10] Z. Maizi, T.Y. Arif, dan Nasaruddin " Evaluasi Algoritma Rate Adaptation untuk Wireless Mesh Network," J. Aceh Phys. Soc., Vol. 7, No. 2 pp.85-91, 2018.

[11] Z. Maizi, " Analisis dan Optimasi Algoritma Rate Adaptation Control untuk meningkatkan Throughput pada Wireless Mesh Network " Universitas Syiah Kuala, Banda Aceh, 2018.

[12] R. Rizki, R. Munadi, and S. Syahrial, "Analisis Performansi Video Streaming Dengan Menggunakan Protokol RTSP Pada Jaringan IEEE 802.11 n," J. Nas. Komputasi dan Teknol. Inf., vol. 2, no. 1, pp. 9-12, 2019.

[13] F. Faisal, R. Munadi, and S. Syahrial, "Analisis Perbandingan Performansi Transmisi Video Dengan Unicast Pada Wlan Ieee 802.11 ac," J. Nas. Komputasi dan Teknol. Inf., vol. 1, no. 2, 2018.

[14] Y. Yanti, N. Pramita, and M. Maulizar, "Analisa Pengukuran Interferensi Pada Acces Point (Ap) Untuk Mengetahui
Kualitas Quality of Service (Qos)," J. Nas. Komputasi dan Teknol. Inf., vol. 1, no. $1,2018$. 